\title{
Study of Low Cost Arc Fault Circuit Interrupter Based on MCU
}

\author{
Shi Li \\ Department of Architectural Engineering, Yulin University, Yulin 719000, China \\ xiangxiang_2002@163.com
}

\begin{abstract}
Arc fault is the arc that may cause damage to the society. Arc is with high temperature and massive heat. If arc fault appears in the low voltage supply environment, it will lead to fire or disaster. So detection and protection of arc fault is essential. In order to prevent the damage of fault arc, a new apparatus named Arc Fault Circuit Interrupter (AFCI) has been proposed. In the paper, arc fault features of the circuit with different load are studied. Then an arc fault detection method is proposed. Then a low cost AFCI is designed so as to promote AFCI. Experimental results show it has the ability to protect the arc fault.
\end{abstract}

Keywords: Arc Fault; Fault Diagnosis; Low Cost; AFCI; UL1699

\section{Introduction}

Arc is a common gas discharge phenomenon in our society. Classified by the stake to human beings, arc can divided into good arc and bad arc [1]. And the bad arc is also known as arc fault. Arc fault often accompany with sparks and high temperature [2]. If appears in the low voltage circuit, it may lead to electrical fire.

Several major accidents make people aware of the hazards of arc fault [3]. So many researchers devote to diagnosis the arc fault. There are three types of arc fault: series arc fault, parallel arc fault and grounding arc fault [4]. Series arc fault often is caused by the interruption of the circuit. Parallel arc fault is a gas discharge between two electrodes with different voltage. If one of the electrodes is ground, the arc fault is grounding arc fault. As series arc fault is Series arc fault is more difficult to be identified, it's meaningful to study the diagnosis method of series arc fault. In the paper, series arc fault is studied.

Many studies have shown that conventional circuit breaker can't protect arc fault. UL1699 standard for arc fault protection is proposed in 1990s [5]. A new apparatus named Arc Fault Circuit Interrupter (AFCI) is introduced. AFCI is a circuit breaker that with the ability to detect arc fault and cut off the circuit so as to reduce the damage caused by arc fault [6]. After 20 years development, there are several types of AFCI

(1) Branch /Feeder Arc Fault Circuit Interrupter. It's an AFCI that installed in the branch circuit or feeder line source (such as a power distribution board), to protect the branch distribution line from the dangers of arc faults.

(2) Combination Arc Fault Circuit Interrupter. It's a socket type AFCI that meet the requirements of branch feeder and can protect its outlet end of the branch line, wire components and power supply wire.

(3) Cord Arc Fault Circuit Interrupter. It's an AFCI that could connect to the plug-in socket output port. It's used to protect the electrical connection to the supply line from the arc on the hazards.

(4) Outlet Circuit Arc Fault Circuit Interrupter. It's often installed in the port of branch circuit, and protects the electrical apparatus and wires that connected to the 
junction boxes from arc fault. It can also provide arc fault protection for the power supply cable assemblies and wires that connected to its lower end [7].

Although there are a variety of AFCI, there is little household installation of it in our country. In order to promote its application, research of AFCI is needed. In the paper, a simple arc fault diagnosis method is present. Then a low cost AFCI is designed based on the arc fault diagnosis method. Experimental results show that the apparatus can effectively protect the arc fault.

\section{Arc Fault Diagnosis Technique}

\subsection{Arc Fault Experiment}

An experiment platform was set up to gather the samples of arc fault. Diagram of the platform is shown in Figure 1.

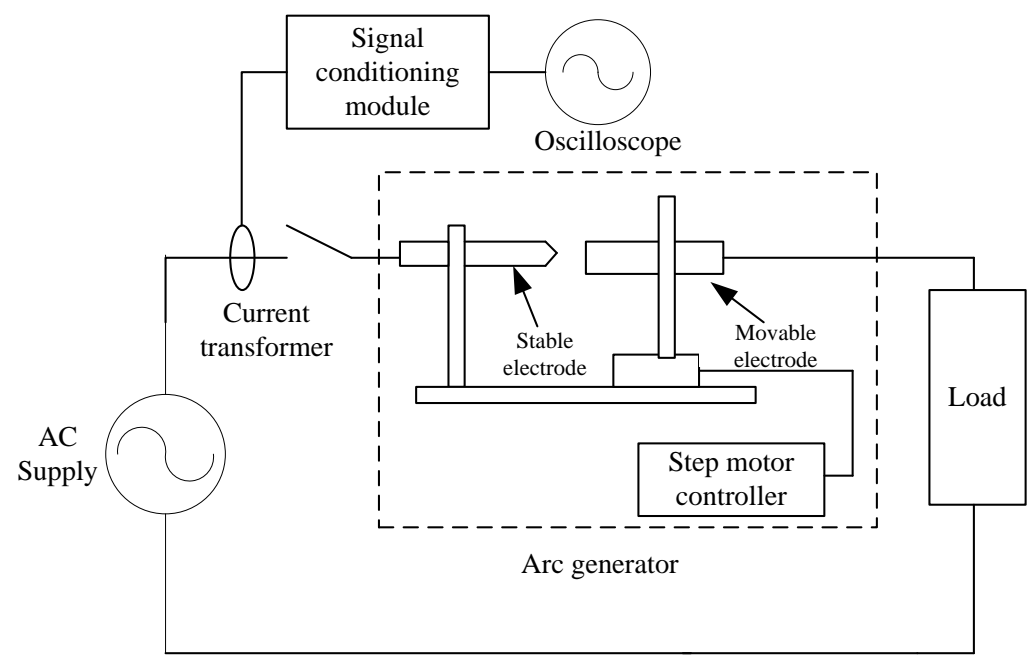

Figure 1. Diagram of Arc Fault Experiment Platform

The platform is consisting of an AC power supply, a current transformer, a signal conditioning module, an oscilloscope and an arc generator. Arc generator above is based on the standard UL1699. It's consisting of a stable electrode and a movable electrode. The movable electrode is driven by the step motor. At beginning, the stable electrode and movable electrode are close together. By separate the movable electrode from stable electrode, arc fault will appear between two electrodes. Arc generator is in series with load so as to generate series arc fault. The arc fault sample data is acquired with the help of oscilloscope. Table 1 summarizes the technical data of experiment platform.

Table 1. Technical Data for the Experiment Platform

\begin{tabular}{rcc}
\hline Index & Name & Parameters \\
\hline 1 & Supply voltage/Rated current & $220 \mathrm{~V} / 50 \mathrm{~A}$ \\
2 & Oscilloscope & TDS-1012B \\
3 & Current transformer & SD-EKADA \\
4 & Step motor driver & Toshiba/THB7128 \\
5 & Step motor & YASKAWA /42HD0401-24 \\
\hline
\end{tabular}

With the help of the experimental platform, voltage and current waveform of different loads were collected. Typical waveform of arc fault with $10 \Omega$ purely resistive load is shown in Figure 2. 


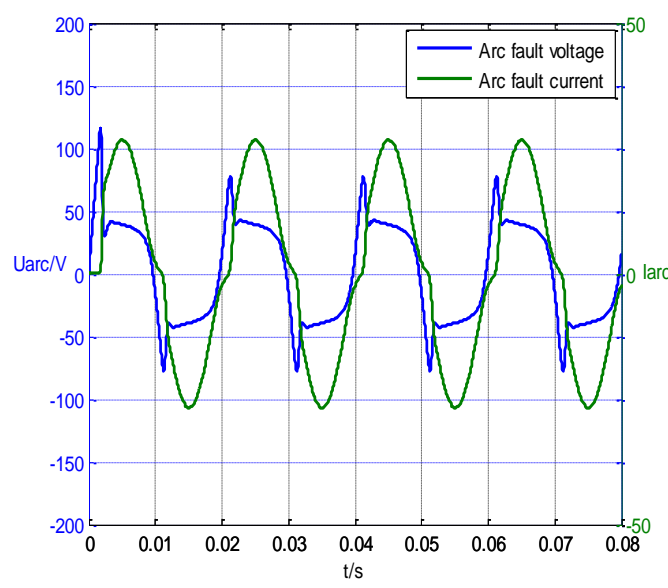

(A) Resistive Load

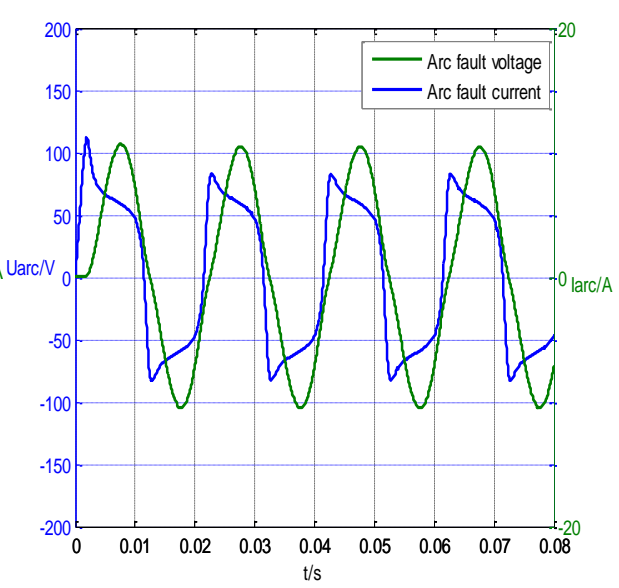

(B) Resistive and Inductive Load

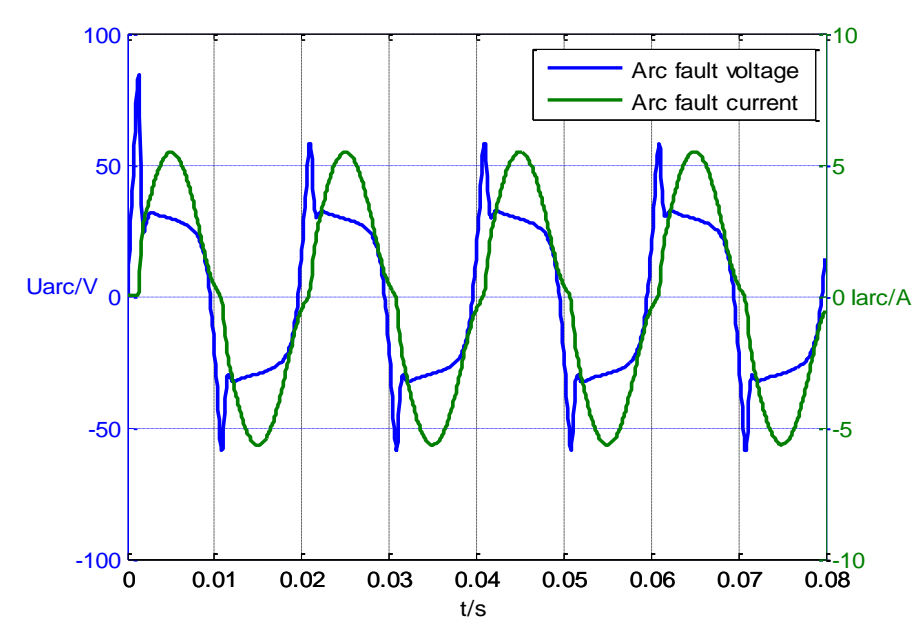

(C)Resistive and Capacitive Load

Figure 2. Arc Fault Current and Voltage Waveform on Different Load

It's obvious that the arc fault current and voltage on different load isn't the same. When the load of circuit is pure resistive, current zero off phenomenon is obvious. When the load of circuit is resistive and inductive or resistive and capacitive, the current zero off phenomenon isn't so obvious. What's more, after the arc current zero, the power supply voltage will be applied to speed quickly on the arc gap due to the arc resistance increases rapidly. It can be concluded that the characteristics of arc fault on different loads are not the same.

A good parameter is needed for arc fault diagnosis for obtain a good test results. Voltage and current of fault arc signals is often chosen. According to figure 2, there is no phase difference between voltage and current waveform of arc fault, which means that arc fault, is a nonlinear resistive load. It's obvious that fault feature of arc fault voltage waveform is more evident than arc fault current. There are two fault arc voltage spikes in each cycle. However, the specific location of the fault arc is difficult to determine in the circuit. The fault arc voltage measuring instruments must be placed at the point that nearby the location of the fault arc, otherwise it is difficult to acquire the arc fault voltage signal. In order to obtain fault arc voltage signals in different regions of the circuit, a large number of sensors need to be set. This will lead to a high cost of arc fault detection. Thus conventional arc fault detection is based on arc fault current signal. In this paper, the acquisition of the 
normal arc fault circuit current waveforms and current waveforms. So as to study the properties of arc fault current.

Figure 3 shows the current waveform of normal sample and arc fault sample. It's clear that the current amplitude of normal sample is higher than the arc fault sample. The arc fault current has a flat shoulder in a half cycle. What's more, there is a 'flat shoulder' in a half cycle of arc fault current.

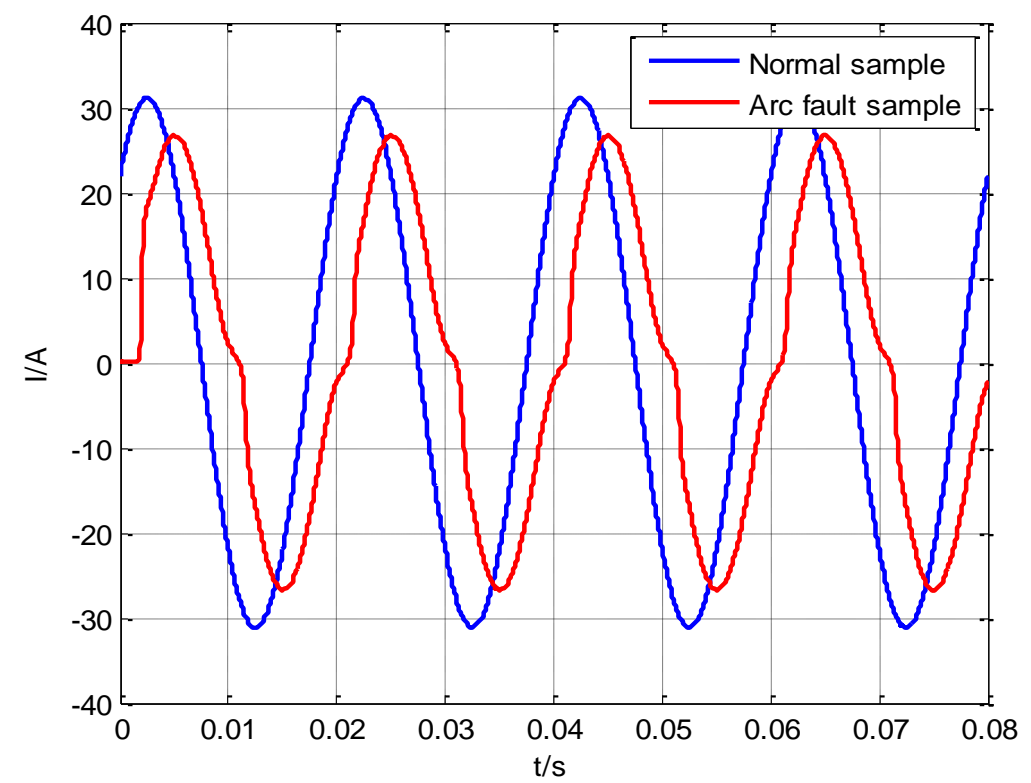

Figure 3. Current Waveform of Arc Fault and Normal Sample

\subsection{Arc Fault Diagnosis Technique}

Before design the AFCI, an effective arc fault diagnosis method is needed. The flowchart of arc fault diagnosis is shown in Figure 4. 


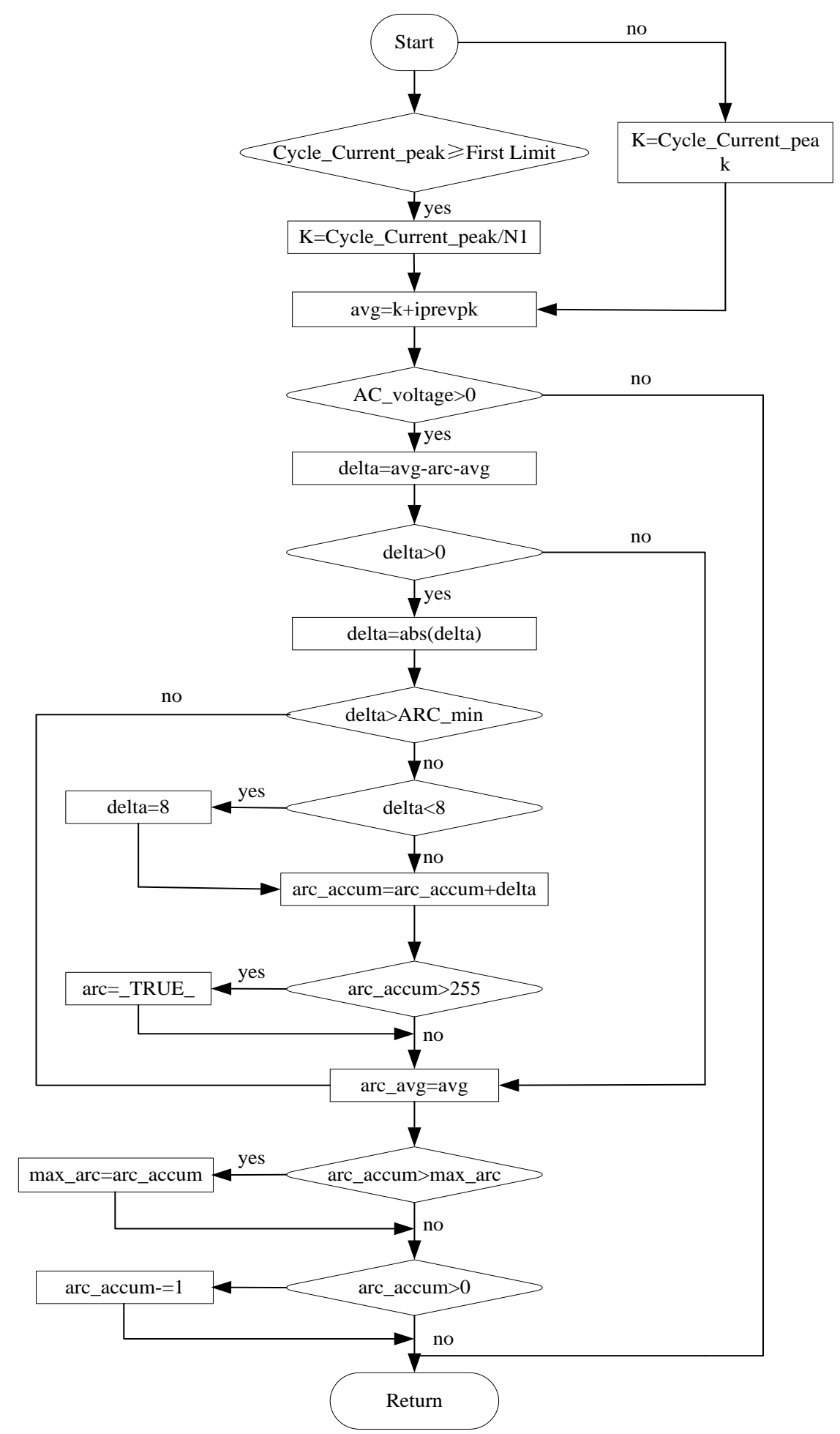

Figure 4. Flowchart of Arc Fault Diagnosis

Considering that the appearance of arc fault will lead to the change of the circuit current, current amplitude is applied into arc fault diagnosis [8, 9, and 14]. After a whole cycle sampling of positive half-cycle current peak and negative half-cycle current peak, average of absolute value of positive half cycle and negative half cycle current peak is calculated. Then the average value is compared with the average of preceding cycle. if the difference is greater than a threshold value, an arc fault is 
diagnosed. Take the difference of a single cycle as the decision will lead to a high misjudgment rate. Therefore, error accumulation of several cycles is chosen as the judgment. If error accumulation of several cycles exceeds the preset threshold, it's considered that there is an arc fault in the circuit.

\section{Hardware of AFCI}

Based on the arc fault detection method above, a low cost AFCI is designed according to standard UL1699. The structure of AFCI is shown in Figure 5. It includes three parts: signal detection part, signal processing part and circuit trip part. Signal of current transformer is sent into a voltage follower, so as to enhance the current signal. Then the current signal is sent into a low pass filter and gain, at last the signal is sent into microcontroller ATmega 16. At the same time, two band pass filters completed the Fourier transform of the signal, and then the result is sent into ATMEGA 16[10]. After diagnosis the signals, AT mega 16 will determine whether there is an arc fault in the circuit.

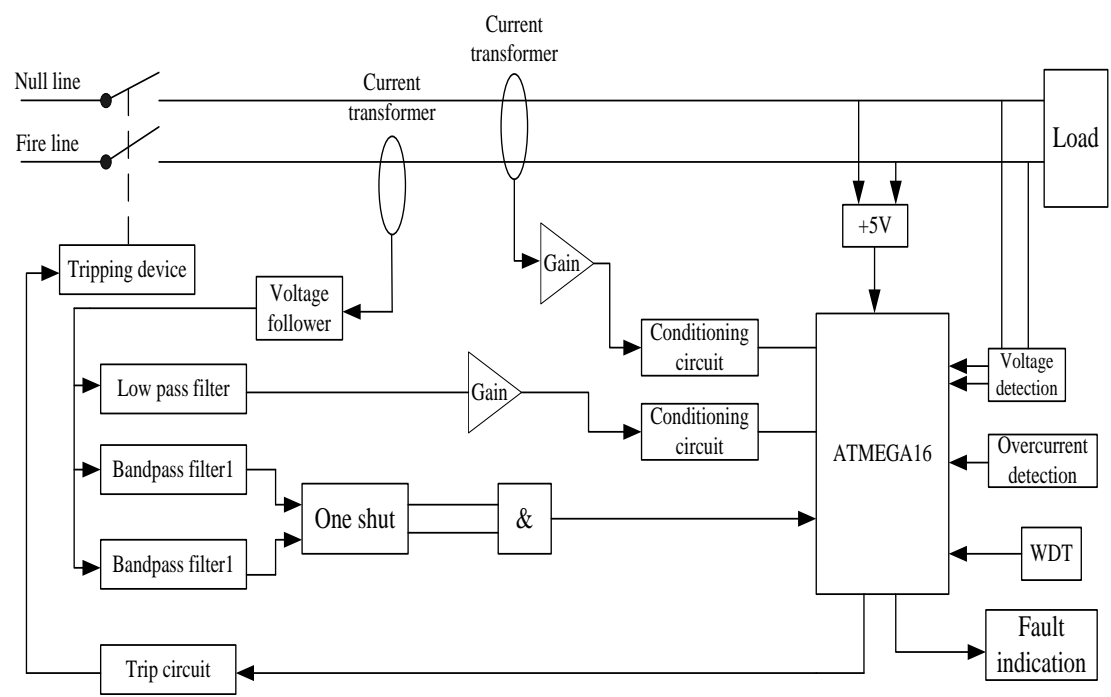

Figure 5. Structure of the AFCI

The Micro controller of AFCI in the paper is ATmega16. Its feature is shown below:

(1) A High-performance with Low-power AVR 8-bit Microcontroller;

(2) Up to 16 MIPS Throughput at $16 \mathrm{MHz}$;

(3) 16K Bytes of In-System Self-programmable Flash program memory, and 512 Bytes EEPROM;

(4) Write/Erase Cycles: 10,000 Flash/100,000 EEPROM [11].

As with high performance and low price, ATmegal6 is chosen as the microcontroller in the paper.

The input of AT mega16 should range from $0 \sim 5 \mathrm{~V}$. While the current of arc fault is alternating, and the signal amplitude is larger than $5 \mathrm{~V}$. So a condition circuit is added in the design. And it is shown in figure 6 [12-14]. 


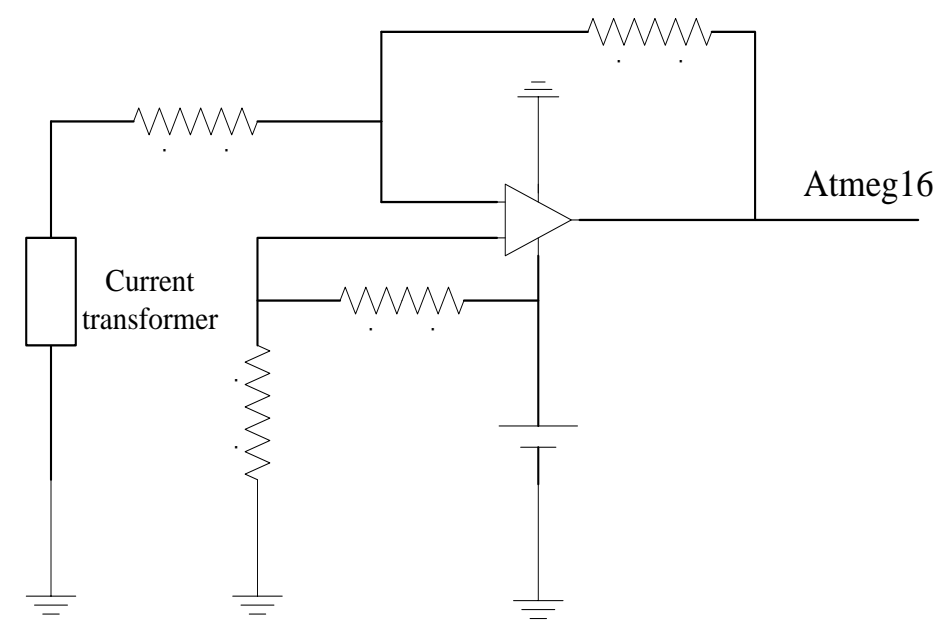

Figure 6. Conditioning Circuit of $\mathrm{AFCl}$

The flowchart of software is shown in Figure 7. After collecting a cycle current data, an arc fault characteristics judge process is taken. In order to avoid fault operation, the arc fault detection is based on three characteristics of arc fault.

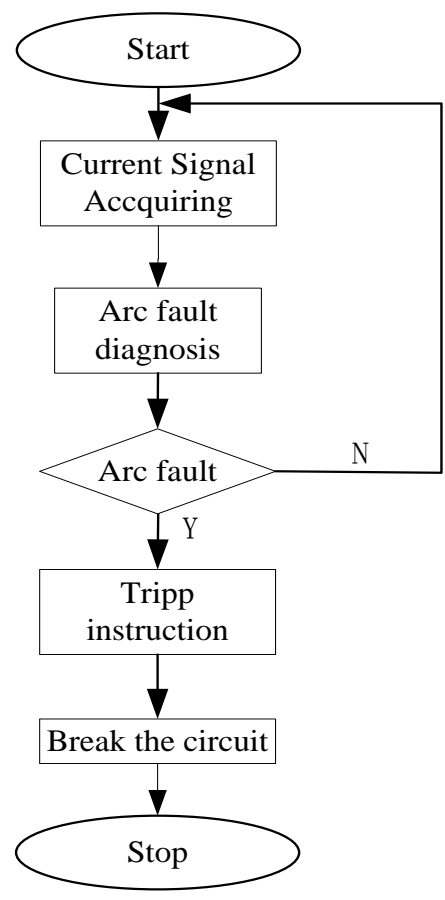

Figure 7. Flowchart of the Software

\section{Test Results}

After design the low cost AFCI, the arc fault experimental platform is improved as a test device so as to assess the performance of AFCI.

In order to analysis the performance of AFCI on different loads, a lot of tests are carried out. When there is an arc fault in the circuit and the AFCI breaks the circuit, we define that the AFCI operates right. The test result is shown in Table 2. It can be concluded that the performance of low cost AFCI on different loads is good. 
Table 2. Test Result of the Low Cost AFCI

\begin{tabular}{|c|c|c|c|}
\hline $\begin{array}{c}\text { Load } \\
\text { characteristics }\end{array}$ & $\begin{array}{c}\text { Resistive } \\
\text { load }\end{array}$ & $\begin{array}{c}\text { Resistive and } \\
\text { inductive load }\end{array}$ & $\begin{array}{c}\text { Resistive and capacitive } \\
\text { load }\end{array}$ \\
\hline Right times & 44 & 41 & 40 \\
\hline $\begin{array}{c}\text { Wrong } \\
\text { times }\end{array}$ & 6 & 9 & 10 \\
\hline Right rate/\% & $88 \%$ & $82 \%$ & $80 \%$ \\
\hline
\end{tabular}

\section{Conclusion}

Arc fault properties are studied in the paper. And an arc fault diagnosis method is present. Then a low cost AFCI based on ATmega 16 is designed according to standard UL1699. Structure and the algorithm of AFCI is present in the paper. After test, the result shown that the arc protection performance of low cost AFCI is very good. And there is little performance difference of AFCI on different loads. While the performance of AFCI need improvement so as to offer a better arc fault protection.

\section{References}

[1] X.J. Xiang and Z. Lin, "The Design of Arc Fault Circuit Interrupter Based on Wavelet Transformation [J]”, Applied Mechanics and Materials, vol.260, pp. 476-481(2013).

[2] J. Johnson, B. Gudgel and A. Meares, "Series and Parallel Arc-Fault Circuit Interrupter Tests", SANDIA REPORT, SAND2013-5916 (2013).

[3] G .Artale, A. Cataliotti, v. Cosentino, "Experimental characterization of series arc faults in AC and DC electrical circuits", 2014 IEEE Instrumentation and Measurement Technology Conference (I2MTC) Proceedings, pp. 1015-1020 (2014).

[4] S. Wang, C. Wu and Y. Wang, "An Effective Detection Method of Serial Arc Fault on Low Voltage Power Circuits", Latest Adv. Syst. Sci. Comput. Intell Conf., Singapore, pp. 177-181 (2012).

[5] S.C. Huang, "Smart Detection of Series Arc Fault on Low Voltage Power Circuits", 2014.

[6] S.C. Wang, H.C. Lee and C.J. Wu, "Signal Detection Technology for Low Voltage Arc Fault Circuit Interrupter Using FPGA", Applied Mechanics and Materials, vol.376, pp. 451-454(2013).

[7] Z. Wang, S. McConnell and R.S. Balog, "Arc fault signal detection-Fourier transformation vs. wavelet decomposition techniques using synthesized data", Photovoltaic Specialist Conference (PVSC), 2014 IEEE 40th. IEEE, pp. 3239-3244(2014).

[8] L.X. Ren and W.L. Wu, "Application of LabVIEW in the development of arc fault circuit interrupters (AFCI)”, Power System Protection and Control, vol.39, pp. 134-138(2011).

[9] H.S. Kim, S.W. Kim, G.P. Gwon, "Multi-level arc fault circuit interrupter with collaborative communications for smart grid", Communications Workshops (ICC), 2010 IEEE International Conference on. IEEE, pp. 1-5(2010).

[10] Q. Wu, R. Zhang, J. Yang, "Research on Arc Fault Detection Devices of Household Air Conditioner", Low Voltage Apparatus, vol.13, 7-12 (2013).

[11] B. Aprahamian and L. Dankov, "A Potential Application of Arc Fault Circuit Interrupters in Ship Electric Systems", Journal of Marine Technology and Environment, vol.3, no. 1(2010).

[12] H. Cheng, X. Guan and L. Guo, "Analysis on Time Frequency Feature of Series Arc Fault", Low Voltage Apparatus, vol.18, 3-7 (2010).

[13] S.H. Ma, J.Q. Bao, Z.Y. Cai, C.Y. Meng, "Research on Arc Fault Characteristics and Detection Method", Mechanics and Materials,pp.133-136 (2013).

[14] G.D. Gregory and G.W. Scott, "The Arc-Fault Circuit Interrupter", An Emerging Product, IEEE Transactions on Industry Applications, vol.34 , no. 5, pp. 928 - 933 (1998). 


\section{Author}

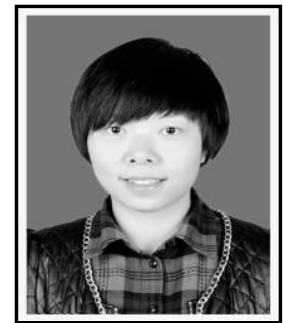

Shi Li was born on November 10, 1983. She is a woman. She is from Shaanxi, China. She is a teacher in Yulin University. She is mainly engaged in research of Engineering management and Building energy efficiency. 
International Journal of Control and Automation Vol.8, No.10 (2015) 